\title{
PRODUCTION POTENTIAL OF BULGARIAN VITICULTURE
}

\author{
A. Roycheva* \\ $\mathrm{PhD}$ student at the Faculty of Economics, Department "Economics", Agricultural University - \\ Plovdiv, Bulgaria
}

\begin{abstract}
Viticulture and wine production are traditional sectors of Bulgarian agriculture, which provide employment and generate revenue for a large part of the population. The membership of the country in the European Union has led to changes in the economic, social and institutional conditions for their development. The concrete manifestation of these changes is related to the production and regional structure, the specialization and concentration of production and institutional support.

The main purpose of the current research is to evaluate the general condition, regional characteristics and the possibilities for development of the production potential of Bulgarian viticulture, through the results from the retrospective analysis and the changes in the institutional medium, which have taken place following the accession of the country to the EU. The dynamics of the production potential in the sector has been analyzed for the period $1961-2013$. by studying the extensive and intensive component. Special attention has been paid to the recent years of sector development, including the influence of transformation and preparation processes connected with the accession of Bulgaria to the EU and the pre-accession funds, as well as the membership period. The current possibilities for the development of the production potential of the viticulture and wine production sector in Bulgaria have been studied, through analyses of the trends in the rate and dynamics of production and export of the sector's products - grape and wine. It has been found that various changes have occurred throughout the separate periods, regarding the age and varietal structure of vineyards, as well as their area.

The possibilities have been outlined for increasing the quantity and quality of production based on a more efficient application of programmes for rural development and development of viticulture and wine production. The institutional prerequisites for broadening of the production potential of Bulgarian viticulture have been assessed.
\end{abstract}

Key words: viticulture, wine production, condition and issues, extensive and intensive component, increasing the production potential.

\section{INTRODUCTION}

Viticulture and wine production are traditional subsectors of Bulgarian agriculture. Although their historical development includes periods of rapid growth, stagnation and decline, they have always provided income and occupation to a part of the population. The soil and climatic conditions in our country are especially favourable for the growing of vines. In the past, the cultivar structure was comprised predominantly of local vine cultivars - more than 100 ones, but currently, introduced

\footnotetext{
${ }^{*}$ Correspondence to: Aneta Roycheva, PhD student at the Faculty of Economics, Department "Economics", Agricultural University - Plovdiv, 12 Mendeleev Blvd., 4000 Plovdiv, Bulgaria, email: aneta.roycheva@abv.bg, tel.: +359887150728
}

cultivars mainly from the West European ecogeographical cluster, are more common, especially in wine production. Bulgaria occupied the first place in the world in terms of table grapes export in 1938, as well as in 1965, when 265000 tons of grapes were exported, mostly from the cultivar Bolgar.

The contemporary problems in viticulture are a direct projection of the social and economic conditions in the country. In addition to the purely technological issues - related to the growing methods, cultivar structure, etc., the lack of a qualified labour factor becomes more pronounced. The specificity of grape production determined by the existing various technological directions, requires certain theoretical and practical characteristics of the 
manpower in the viticulture sector. The age structure of vines has also changed over the recent decades. New vineyards were created by companies different in scale and structure, but in spite of this, the planted area remains significantly smaller compared to that in 1969 200700 ha. The standards for grape have changed as well, focusing on its qualitative rather than quantitative parameters. All these processes characterize viticulture as a dynamic system which has the potential to develop in the current conditions.

The management of the viticulture and wine production sector in Bulgaria is performed by the Council of Ministers, and the operational governance of the sector is delegated to the Minister of Agriculture and Food. The Executive Agency on Vine and Wine (EAVW) with the Minister of Agriculture and Food is the state controlling institution in the sector. The viticulture and wine production sector is one of the first economic sectors to be allowed by the legislation a high degree of self-regulation, conducted by the National Viticulture and Wine Production Chamber.

\section{CONDITION AND DYNAMICS OF THE PRODUCTION POTENTIAL OF BULGARIAN VITICULTURE}

The development of the viticulture and wine production sector in Bulgaria is determined by a number of factors, the most important of them being the favourable environmental and climatic conditions for production, its zoning and micro-zoning and the related capacity of local and introduced cultivars, i.e. a capacity for the production of high quality wines.

At the present stage of sector development, several problems are observed, connected predominantly with the necessity for legislative amendments aiming at consolidation of land property and regulation of the registration process for vineyards, necessity for increasing the efficiency of the financing mechanisms in the sector, etc. The most significant problem defined is the reduced production potential of the Bulgarian viticulture and wine production sector, which includes decreased areas and production, declining average yield, limitation of the market capacity and reduction of sector income.

The age structure of the majority of vineyards in Bulgaria is not favourable due to the fact that a significant part of them were planted more than thirty years ago. There is a low relative share of newly developed vineyards and aging of plantations takes place - the share of newly developed vineyards does not correspond to the need for reproduction of wine vineyards. The poor condition of vineyards is determined not only by the unfavourable age structure, but also by the untimely and irregular agrotechnological care applied. The main reasons for that include the delay in the land reform and the existing problems related to financing in the sector. Currently, the vineyards in a good condition are approximately $33 \%$, and the share of restored plantations is $52 \%$. (1)

The cultivar structure of the sector is a significant factor in wine production. The red wine cultivars form $52 \%$ of vines in Bulgaria, and white ones $-32 \%$. According to data from the "Agrostatistics" Section of the Ministry of Agriculture and Food, the vineyard area in 2013 amounts to 63136 ha. The total grapes production for the same year is 325596 tons. (2)

\section{INFLUENCE OF THE EXTENSIVE AND INTENSIVE COMPONENTS}

Production potential is a complex concept based on the indication of a wide range of interrelated parameters. It is formed as an aggregation of all factors influencing the potential of the sector, i.e. determining its actual capacity. In this regard, the production potential shows the maximum capacity of the sector to achieve a certain production result. The production potential in agriculture is determined by the area planted with the corresponding crop, multiplied by the quantity of yield for the studied period.

The extensive component is related to the changes in the size of planted area, i.e. the growth of production is a result of the increase in vineyard areas. The intensive component concerns technological developments, which lead to a rise in average yield. The influence of these two components on the production potential is graphically presented on Figure 1.

Resource: Food and Agriculture Organization
of the United Nations: FAOSTAT:
http://faostat.fao.org/ (3)

On the basis of the data from the retrospective analysis for 1961 - 2013, five periods with different duration can be identified. The main features and borders of these periods are determined according to three indices and their dynamics and interrelations: vineyard area, yield and production potential. 


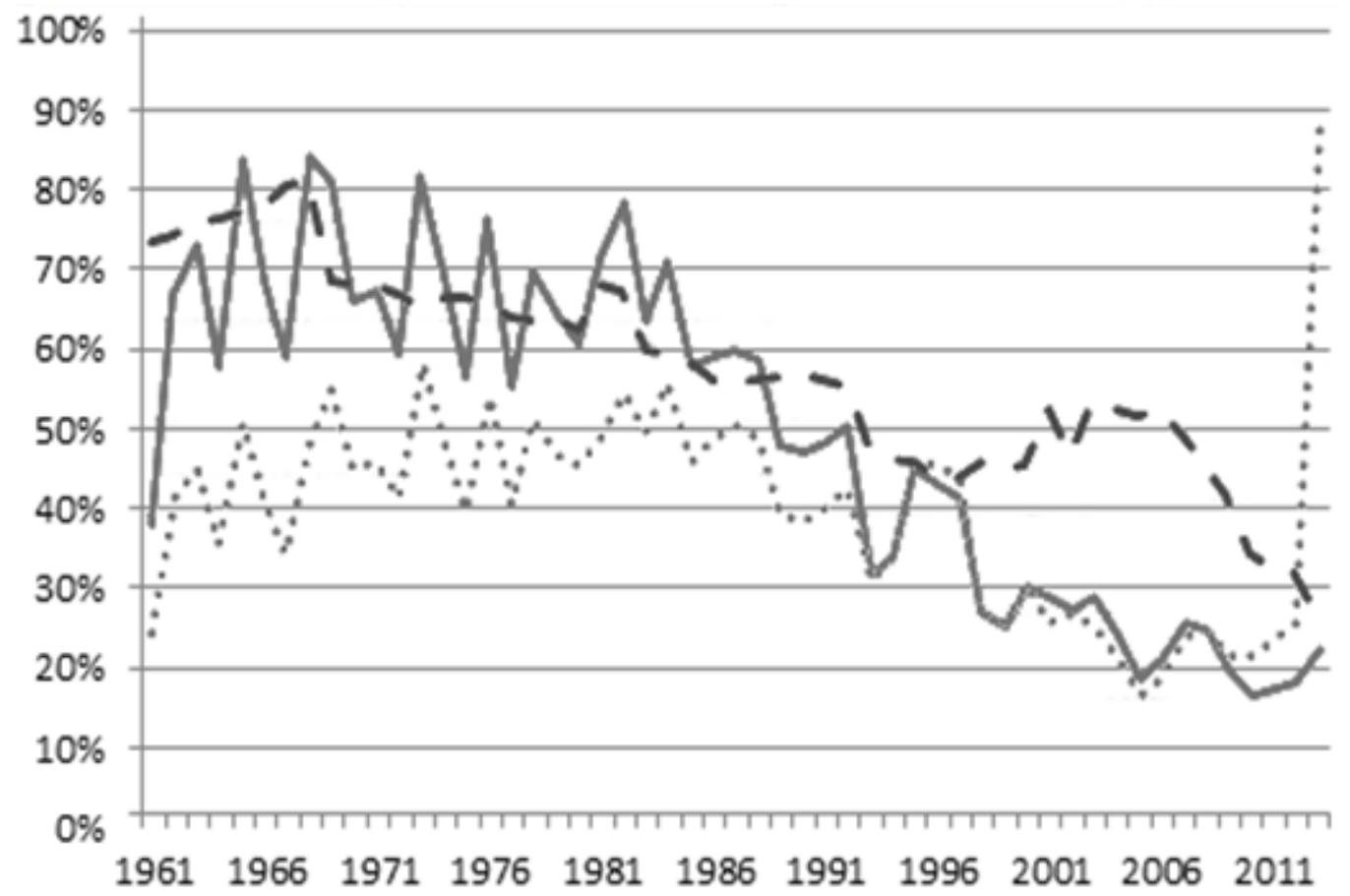

- - Area harvested ..... Yield - Production

Figure 1. Influence of the extensive and intensive components

The first period encompasses 1961-1969. During the studied period, a clearly defined trend is observed of increasing of the production potential of viticulture, which is mainly caused by the rise of average yield (the intensive component), which from $3182,7 \mathrm{~kg} / \mathrm{ha}$ reaches $7565 \mathrm{~kg} / \mathrm{ha}$. Negative influence is exerted by the extensive component (area) - at the beginning of the period the area is 182000 ha, and it decreases to 169900 ha in 1969. At the beginning of the period the production potential amounts to 579260 tons, and at its end it reaches 1285294 tons, i.e. the average annual rate of increase amounts to $148,9 \%$.

The second period includes the years from 1970 to 1982. A slow decrease in grape production is observed in comparison with the previous stage, which is due to the negative influence of the extensive component - vineyard area is reduced from 169196 ha at the beginning of the period to 166988 ha at its end. This influence exceeds the positive effect of the rise in the intensive component, which increases by $1317,3 \mathrm{~kg} / \mathrm{ha}$.

The third period includes 1983 - 1991. The production potential decreases significantly - by 252323 tons or $25,2 \%$ as a result of the negative influence of both the intensive and extensive component. Their values fall correspondingly by $1368,6 \mathrm{~kg} / \mathrm{ha}$ and $9296 \mathrm{ha}$. This period is characterized by a limitation of the influence of the Soviet market - the Soviet
Union conducts a policy of restriction of the consumption of alcohol drinks and wine. The imposed quota leads to a reduction in the exported quantities of wine for the Soviet Union. These circumstances force the shrinking of vineyard areas, primarily by removing the old plantations with lower productivity and bad economic and agrobiological indices. Mostly younger vineyards remain, which eventually leads to the stabilizing of the production potential from 1985 to 1988 at a relatively constant level. In 1989 a new lower quota is introduced, which causes further limitation of export, respectively production. The production rate is stabilized again by 1992 .

The fourth period $-1992-2005$. The social and economic changes in Bulgaria since 1989 exert their influence on the viticulture and wine production sector of the country. Following 1991, the consequences of the restructuring of property begin to manifest themselves. The result is a reduction in the produced quantity of grape by 521031 tons, i.e. by 66,1\% - from 787214 tons in 1992 to 266183 tons in 2005 .

The fifth period - 2006 - 2013, is highly dynamic since it includes the pre-accession phase and the accession of Bulgaria to the European Union. The SAPARD programme (Special Accession Programme for Agriculture and Rural Development) functions through this period. Large-scale wineries are established and 
a rise in production occurs since 2005. In 2007 , the wineries unofficially refuse to buy grapes from producers and this forces small producers to reduce the quantities. The membership of Bulgaria in the European Union reveals broad new perspectives for the sector. A process of gradual aggregation of vineyard land lots begins.

The average values per year of area harvested, yield and production of grapes during the five studied periods are shown in Table 1.

Table 1. Average values per year of area harvested, yield and production of grapes during the researched periods

\begin{tabular}{|c|c|c|c|}
\hline Periods & $\begin{array}{c}\text { Area harvested } \\
(\boldsymbol{h a})\end{array}$ & $\begin{array}{c}\text { Yield } \\
(\boldsymbol{k g} / \boldsymbol{h} \boldsymbol{a})\end{array}$ & $\begin{array}{c}\text { Production } \\
(\text { ton })\end{array}$ \\
\hline $\begin{array}{c}\text { I period } \\
\mathbf{1 9 6 1}-\mathbf{1 9 6 9}\end{array}$ & 189423,6 & 5674,2 & 1072996,6 \\
\hline $\begin{array}{c}\text { II period } \\
\mathbf{1 9 7 0}-\mathbf{1 9 8 2}\end{array}$ & 163235 & 6511 & 1062770,4 \\
\hline $\begin{array}{c}\text { III period } \\
\mathbf{1 9 8 3}-\mathbf{1 9 9 1}\end{array}$ & 141120,6 & 6318,7 & 892890,7 \\
\hline $\begin{array}{c}\text { IV period } \\
\mathbf{1 9 9 2}-\mathbf{2 0 0 5}\end{array}$ & 118415,9 & 4201,3 & 492548,7 \\
\hline $\begin{array}{c}\text { V period } \\
\mathbf{2 0 0 6}-\mathbf{2 0 1 3}\end{array}$ & 95383,5 & 4145,1 & 298622,8 \\
\hline
\end{tabular}

Resource: Own calculations based on data from FAOSTAT: http://faostat.fao.org/ (3), the Food and Agriculture Organization of the United Nations: http://www.fao.org/home/en/ (4), and the National Statistical Institute, Section Agriculture and Forestry; Section Business Statistics: http://www.nsi.bg (5)

The most important conclusion derived from the conducted research is related to the fact that the production potential of Bulgarian viticulture has been reduced throughout the last twenty years.

The economically significant aspects of the problem can be summarized as follows:

- Reduction of areas and production;

- Decreasing average yield;

- Limitation of market capacity;

- Reduction of sector income.

\section{POSSIBILITIES FOR INCREASING THE PRODUCTION POTENTIAL IN THE SECTOR}

The possibilities for increasing the production potential of Bulgarian viticulture are connected with a number of European sector support programmes. During the pre-accession phase, by means of the financing provided by SAPARD programme and the State Fund "Agriculture" (investment programme "Horticulture", "Regional programme for North-West Bulgaria", "Programme for development of alternative agriculture in the Rhodope Mountains" and "Programme for development of agriculture and rural regions in Strandzha-Sakar"), the processes of development of new vineyards and reconstruction of currently existing ones intensified. Through the State Fund "Agriculture", 2120 ha of new wine vineyards were created and 200 ha of table ones were reconstructed for the period $1999-2002$. By SAPARD programme projects for reconstruction of 121 ha of wine vineyards were developed and approved for the period 2001 2002. According to data from the Ministry of Agriculture and Food, 169 projects were approved by measure 1.1. from SAPARD programme "Investments in agricultural organizations" by the end of 2007. During the period $2002-2007,185$ projects were approved for the development/reconstruction of 4398,8 ha of vineyards by programme "Horticulture".

After the accession of Bulgaria to the European Union in 2007, some of the measures included in the National programme received partial financing by I and II pillar of the Common Agricultural Policy (CAP) 2007 2013. The Rural Development Programme with its direct payments also contributes to the increasing of the production potential.

The rise of the production potential of Bulgarian viticulture at the current stage of development should be pursued in several major directions, which can be generally classified as technical, organizational and institutional.

Technical possibilities for increasing of the production potential are related to improving production efficiency, minimizing risk, limitation of the influence of environmental factors, etc. Technological advances and the acceleration of innovation processes include the development of new vine cultivars with better ampelographic parameters, enlarging of 
vineyard areas and restoration of plantations with a worsened agrotechnological status, application of contemporary production equipment and maintenance devices. Innovations in the production process are a powerful motivation mechanism for production expansion and for attracting of new producers to the sector. Innovations can be directed at optimization of the production quantity, as well as at optimization of the production costs or at both aspects simultaneously, i.e. the technological advances are an instrument for optimization of the relations between used production factors and the produced quantity of goods (the production function). Through innovations it is possible to successfully reduce some of the negative aspects of grape production such as the typical longer duration of the production cycle. The application of new technological options aimed at providing conditions for longer storage of grapes, can allow the producers to extend the period of market supply and thus to diminish the influence of the seasonal nature of production and supply of goods in agriculture. The immediate effect of technological innovation is expansion of production and supply and increasing of the absolute profit of economic subjects occupied in the sector. (6)

Organizational prerequisites encompass the providing of open access to and an equitable distribution of resources, as well as development and improvement of the production and social infrastructure by adoption of good production practices. It is necessary to reduce the length of the

supply chain and to facilitate the interaction between producers and end consumers, which can be achieved by establishing producers' organizations or other forms of association. The organizational mechanisms are also related to optimization of the employment structure in the sector - providing qualified manpower, improving the age structure of the workforce by stimulating and attracting young entrepreneurs to start business in the sector by increasing its profitability, etc.

Institutional factors contribute to the increasing of the production potential by optimizing the institutional medium and the public decision taking model. The institutional medium is a system of social, political and legislative norms. The institutional structure of market economy includes the direct agents of market relations business organizations, state and financial institutions interacting with the market and its subjects in accordance with the aggregation of institutional behavioral norms. The efficient functioning of the institutional medium is determined to a great extent by the broadening of the access to information on the dynamics of the medium parameters. The full absorption of European and other funds and the adequate market behaviour depend largely on the timely informing of producers. It is also necessary to develop special legislative acts encouraging the enlargement of vineyards, thus the consolidation processes will facilitate the overcoming of administrative and institutional limitations in regard to the access to financial support by the EU. (7)

The possibilities for increasing the production potential of Bulgarian viticulture are based on a comprehensive analysis of the condition of the sector and the formulation of a national strategy for enhancing its competitiveness on the internal and external market. The stimulation of investments in the sector through European financing mechanisms such as the Common Agricultural Policy 2014 - 2020, is a vigorous instrument for solving issues and instigating sector development.

\section{REFERENCES}

1. National strategy for the development of viticulture and wine production in the Republic of Bulgaria 2005-2025, Council of Ministers, Portal for public consultation, Section Strategic documents: http://www.strategy.bg/StrategicDocuments/ View.aspx ?lang=bg-BG\&Id=354

2. Ministry of Agriculture and Food, Section "Agrostatistics":

http://www.mzh.government.bg; survey "Production of grapes and wine - harvest '2013"

3. Food and Agriculture Organization of the United Nations: FAOSTAT: http://faostat.fao.org/

4. Food and Agriculture Organization of the United Nations: http://www.fao.org/home/en/

5. National Statistical Institute, Section Agriculture and Forestry; Section Business Statistics: http://www.nsi.bg

6. Angelova, V., Agricultural economics, p. 156-174. University press "Economics", University of National and World Economy, Sofia, 1999.

7. Dimitrova, D., Competitiveness of the production of table grapes. PhD dissertation, Agricultural Academy, Institute of Agricultural Economics, Sofia, 2015. 